\title{
MINERAL TRIOXIDE AGGREGATE VERSUS BIODENTINE AS RETROGRADE FILLING MATERIAL- A CLINICAL REVIEW
}

\author{
Sanjeev Srivastava ${ }^{1}$, Ajay Paliwal2, Isha Srivastava ${ }^{3}$, Saraswati Sachan ${ }^{4}$, Vineet Shah ${ }^{5}$
}

${ }^{1}$ HOD, Department of Conservative Dentistry and Endodontics, Sardar Patel Post Graduate Institute of Dental and Medical Sciences, Lucknow.

${ }^{2}$ Reader, Department of Conservative Dentistry and Endodontics, Sardar Patel Post Graduate Institute of Dental and Medical Sciences, Lucknow.

${ }^{3}$ Post graduate Student, Department of Conservative Dentistry and Endodontics, Sardar Patel Post Graduate Institute of Dental and Medical Sciences, Lucknow.

${ }^{4}$ Post graduate Student, Department of Conservative Dentistry and Endodontics, Sardar Patel Post Graduate Institute of Dental and Medical Sciences, Lucknow.

${ }^{5}$ Senior Lecturer, Department of Prosthodontics, Crown and Bridgework and Oral Implantology, Faculty of Dental Science, Dharamsinh Desai University, Nadiad, Gujrat

\section{ABSTRACT}

\section{BACKGROUND}

The ultimate goal of root canal treatment is to seal the root canal both apically and coronally through obturation and restoration in order to prevent recontamination of the disinfected canals. Even after root canal treatment, there can be problems due to failure. The major causes of root canal failure are persistence of microbes or entry of microbes through coronal or apical leakage. If the reinfection occurs, in most of the cases surgical intervention is required followed by retrograde filling to achieve hermetic apical seal. Various retrograde filling materials have been advocated but MTA was found to be more appropriate as the literature suggested. However, Biodentine has also been used since last few years. The aim of the retrograde filling is to seal the canal in order to prevent passage of bacteria or their toxins from the canal space into peri-radicular tissues and vice versa. MTA and Biodentine has been shown to have a biocompatible nature and have excellent potential in endodontic use.

The aim of this article is to comparatively review the properties such as biocompatibility, sealing ability, antibacterial effect and tissue response in both MTA and Biodentine as root-end filling material.

\section{KEYWORDS}

MTA, Biodentine, Retrograde filling material.

HOW TO CITE THIS ARTICLE: Srivastava S, Paliwal A, Srivastava I, et al. Mineral trioxide aggregate versus Biodentine as a retrograde filling material- a clinical review. J. Evolution Med. Dent. Sci. 2017;6(44):3482-3486, DOI: 10.14260/Jemds/2017/752

\section{BACKGROUND}

Apical leakage of bacteria and their by-products from contaminated canal space is the major cause of periapical lesion after conventional endodontic treatment or retreatment. When non-surgical re-treatment has failed or cannot be performed, surgical intervention is indicated. Surgical intervention comprises periapical curettage with resection of the root apex and filling a prepared cavity at the root-end with a retrograde filling material. The objective of the retrograde filling is to seal the root canal to prevent passage of bacteria and their by-products from the canal space into periradicular tissues. Root-end filling material comes in direct contact with periapical tissues. Therefore, tissue response of the root-end filling material becomes important and influences the outcome of surgical endodontic treatment. Sealing with a root-end filling material creates a 'biological seal,' and 'physical seal', thereby creating a 'double seal'.1 Moreover, apical curettage without the root-end filling

Financial or Other, Competing Interest: None.

Submission 27-04-2017, Peer Review 21-05-2017,

Acceptance 27-05-2017, Published 01-06-2017.

Corresponding Author:

Dr. Isha Srivastava,

Postgraduate Student,

Department of Conservative Dentistry and

Endodontics, Sardar Patel Post Graduate

Institute of Dental and Medical Sciences,

Lucknow, Uttar Pradesh.

E-mail: ishasri2610@gmail.com

DOI: $10.14260 /$ jemds $/ 2017 / 752$ may not produce a fluid tight seal. J Aqrabawi in 2001 showed the importance of root-end filling material by reporting that teeth with root-end fillings showed best results when compared to teeth without root-end fillings. ${ }^{2}$

A plethora of restorative and endodontic materials have been suggested over the years for root-end filling such as amalgam, glass ionomer cement, zinc oxide eugenol cement, Gutta-percha, composite resin. Recently, newer materials are bioceramic putty, iRoot BP Plus (Innovative BioCeramix Inc., Vancouver, Canada), novel root-end filling material (new resin cement), Capasio powder (Quick-Set), BioAggregate, polymer nano composite resin, Ceramicrete. Due to some disadvantages, Amalgam, GIC, Composite resin are not used nowadays. $^{3}$ Recently, mineral trioxide aggregate and Biodentine are used.

MTA is a material of choice for root-end filling during apical surgery and intentional replantations due to its properties. It is a compound mixture of hydrophilic tricalcium silicate, tricalcium oxide, and tricalcium aluminate with some other oxides. An independent analysis reveals that MTA is identical to Portland cement with the addition of bismuth oxide. Initially, MTA was formulated as a grey powder, but white MTA was later developed to overcome tooth discolouration by the grey formula (Dammaschke et al 2005).4 Felman and Parashos, 20135; Camilleri, $2013^{6}$ advocated that white MTA also induces the unaesthetic appearance. The difference between two forms of MTA (Grey MTA and white MTA) has been reported to be in the concentrations of aluminium, magnesium, and iron 
compounds. White MTA lacks the alumino-ferrite phase that imparts the grey colour.5,6

Sluyk et al (1998), ${ }^{7}$ Torabinejad et al (1999) ${ }^{8}$ and Schmitt et al $(2001)^{9}$ advocated that the powder-water ratio for MTA should be $3: 1$. It is advised to place a wet cotton pellet over the MTA in the first visit to avoid degradation by moisture as it is hydrophilic in nature and replaced by a permanent restoration at the second visit. MTA has a pH of 10.2 after mixing. After 3 hours of setting, the $\mathrm{pH}$ increased to 12.5 . Sluyk et al (1998) ${ }^{7}$ advocated that mixing time should be less than 4 minutes. Torabinejad et al (1995) ${ }^{10}$ found setting time about 2 hours and 45 minutes. According to the density of the air entrapped during mixing, working time is almost $5 \mathrm{~min}$. and hardening time varies from $2 \mathrm{hrs}$. \& $45 \mathrm{~min}$. to $4 \mathrm{hrs}$.

A novel material Biodentine was introduced in September 2010 as a root-end filling material. Biodentine is considered as bioactive and biocompatible dentine substitute material designed to replace damaged dentine both for restorative and endodontic purposes such as root perforations, apexification, resorptive lesions, and also as a retrograde filling material in endodontic surgery. ${ }^{11}$

The powder contains dicalcium silicate, tricalcium silicate, calcium carbonate and iron oxide, and zirconium oxide filler. Liquid consists of calcium chloride which acts as an accelerator and a polymer which acts as a water reducing agent. Tricalcium silicate $\left(3 \mathrm{CaO} \cdot \mathrm{SiO}_{2}\right)$ regulates the setting reaction, dicalcium silicate $\left(2 \mathrm{CaO} . \mathrm{SiO}_{2}\right)$ acts as a core material, calcium carbonate $\left(\mathrm{CaCO}_{3}\right)$ acts as a filler. Zirconium dioxide $\left(\mathrm{ZrO}_{2}\right)$ is added to provide the radio-opacity to the cement. Calcium chloride $\left(\mathrm{CaCl}_{2} .2 \mathrm{H}_{2} \mathrm{O}\right)$ act as an accelerator. ${ }^{12}$ The working time of Biodentine is up to 6 minutes and final setting time is from 10-12 minutes from the start of mixing until the indentor fails to leave a mark on the set material surface. ${ }^{13}$

The purpose of this review article is to discuss the important properties of MTA and Biodentine as retrograde filling in all perspective.

\section{Comparative Properties of MTA and Biodentine Mechanism of Action}

When MTA is placed in direct contact with human tissues, it appears that the material does the following: (1) Cell attachment and proliferation occurs by release of calcium ions, (2) alkaline $\mathrm{pH}$ produces antibacterial effect, (3) Modulates cytokine production, (4) hard tissue-producing cells initiate differentiation and migration. (5) MTA surface forms carbonated apatite and biologic seal is created. ${ }^{14}$

Biodentine increases early mineralisation by expressing markers of odontoblasts and induces TGF-Beta1 secretion from pulpal cells in form of osteodentin. Calcium hydroxide is formed which is responsible for its high $\mathrm{pH}$, provokes the irritation at the area of exposure. It initiates division and migration of precursor cells to substrate surface followed by addition and cyto-differentiation into odontoblast like cells in zone of coagulated necrosis. ${ }^{15}$ Apposition of reactionary dentine by odontoblast stimulation and reparative dentine by cell differentiation is increased. ${ }^{16}$

\section{Cytotoxicity, Biocompatibility and Bioactivity}

MTA is biocompatible, produces conducive environment for healing with no adverse effects on the dental tissues.10,17,18 It was suspected that freshly mixed MTA might create a detrimental environment for cells because it has a high $\mathrm{pH}$ during setting. ${ }^{19}$ MTA is bioactive due to its positive host response as hard tissue induction properties. ${ }^{20}$ Thick cementum was deposited on the surfaces of MTA root-end fillings, which assures MTA to be bioactive. ${ }^{10,18}$ It is capable to promote hard tissue formation. ${ }^{10,21}$ It is evaluated that MTA promotes formation of bone by inducing osteogenic cell differentiation. ${ }^{22}$

Biodentine is non-toxic, inorganic, non-metallic and has no unfavourable effects on cell differentiation and target cell function. It is non-cytotoxic and non-genotoxic for pulp fibroblast at any concentration. ${ }^{23}$ However, Biodentine when it comes in direct contact with connective tissue, cell death occurs due to apoptosis or necrosis. Laurent et $\mathrm{al}^{24}$ was the first to show the promising biological properties of Biodentine on human fibroblast cultures and reported that angiogenesis, recruitment of progenitor cell by inducing odontoblasts differentiation, and cell differentiation generates deposition of a reactionary dentine as well as dense dentine bridge. The mineralisation occurs by increase in growth factor TGF-B1 secretion from pulp cells.

\section{Sealability}

Shipper et al (2004)25 and Torabinejad et al (1995) ${ }^{10}$ concluded that MTA expands during setting reaction as it has tremendous sealing ability. Moistened cotton pellet must be placed over MTA before placement of the permanent restoration as MTA has better sealing ability when it is exposed to moist environment. Valois et al (2004) ${ }^{26}$ concluded for a better sealing ability, $4 \mathrm{~mm}$ thickness of MTA is required. Aminoshariae et al (2003) ${ }^{27}$ showed that hand condensation was better than ultrasonic method as the MTA has a better adaptation to the walls with less voids in it.

However, during setting reaction of Biodentine, micromechanical adhesion occurs because of its high alkalinity. High $\mathrm{pH}$ causes organic tissue to disintegrate out of the dentinal tubule. Dentine substitute mass can find a path via exposed opening of the dentine canaliculi because the alkaline environment occurs at the boundary area of contact between Biodentine and hard tooth substance. It induces Biodentine to be keyed by means of bacteria tight effect, innumerable microscopic cones and creating a stable anchorage with a sealing ability. ${ }^{17}$

\section{Compressive Strength}

Torabinejad M et al (1995) ${ }^{10}$ found that compressive strength of white MTA is lesser as compared to that of grey MTA and evaluated that compressive strength at 24 hours is $40.0 \mathrm{MPa}$ and at 21 days is $67.3 \mathrm{MPa}$.

Biodentine is having the higher compressive strength when it is compared to MTA because of low water-powder ratio. As the time passes, compressive strength of Biodentine is $300 \mathrm{MPa}$ which is in a similar range of natural dentine i.e., $297 \mathrm{MPa}$.

\section{Radiopacity}

Radiographically, MTA is easily noticeable as it is having radiopacity equalling to $7.17 \mathrm{~mm}$ thick of aluminium sheet. Because it is more radiopaque than conventional Guttapercha and dentin, it should be easily distinguishable on radiographs when used as a root filling material (Torabinejad $\mathrm{M}$ in 1995).11 
In Biodentine, Zirconium oxide is used as a radiopacifier whereas, bismuth oxide is used as a radiopacifier in MTA. Zirconium oxide is considered as a better bio-inert material, resistant to corrosion and has better biocompatibility. Therefore, Biodentine provides more radiopacity than MTA. ${ }^{28}$

\section{Solubility}

MTA shows increased solubility when extra water is mixed during manipulation, but it is insoluble when it sets. Budig stated that when water comes in contact with set MTA, calcium hydroxide is released which initiates cementogenesis. ${ }^{29}$

Grech et al reported that Biodentine is insoluble. Hydroxyapatite crystals were formed on surface when it comes in contact with synthetic fluids and it is dimensionally stable as this material does not lose any particulate matter. But when it is compared with MTA, Biodentine has higher solubility. ${ }^{30}$

\section{Antibacterial and Antifungal Property}

Al Hazami et al reported that MTA has better anti-bacterial properties against E. faecalis, S. aureus and P. aeruginosa when compared with other materials. ${ }^{31}$ Torabinejad et al (1995) ${ }^{32}$ reported that facultative bacteria has some certain effects on MTA and no antimicrobial action was found against anaerobes.

In Biodentine, growth of micro-organisms is inhibited and disinfects the canal by the release of calcium ions during setting reaction which raise the $\mathrm{pH}$ to $12.5 .{ }^{13}$ However, Biodentine showed higher antimicrobial activity against S. mutans because it contains more potent antibacterial and antifungal inhibitors than MTA.

\section{Microleakage}

MTA is hydrophilic in nature, as it undergoes setting expansion when it is dried in moist environment and thus the presence of moisture in the surgical field does not affect its setting or the properties. MTA showed better marginal seal when compared with Biodentine because of the formation of the hydroxyapatite like crystals at the interface between material and canal wall. It prevents the penetration of the dye by superior adhesion quality. Moreover, microleakage of MTA was comparatively lesser than Biodentine.

\section{Bond Strength}

Aggarwal et $\mathrm{al}^{33}$ compared the push-out bond strength of Biodentine and MTA in furcation perforation repairs and as a retrograde filling material, evaluated that after $24 \mathrm{hrs}$., MTA had less push-out strength than Biodentine. Higher bond strength is achieved with a total-etch single-bottle adhesive with a resin-based composite or compomer than single-step self-etch system over MTA. ${ }^{34}$

Guneser et $\mathrm{al}^{35}$ stated that when Biodentine is exposed to $\mathrm{NaOCl}$, chlorhexidine and saline irrigating solutions exhibit better repair material when compared with MTA. Biodentine has sufficient amount of push out bond strength to prevent dislodgement from operating site than MTA.

\section{Discolouration}

A tooth immersed in sodium hypochlorite when comes in contact with MTA results in colour alteration at the cement/dentine interface. MTA should not be used after irrigation with sodium hypochlorite as it results in tooth discolouration. ${ }^{36}$

Biodentine exhibits colour stability over a period of 5 days when exposed to oxygen and light conditions and spectrophotometric analysis. It serves as an alternative for light-cured restorative materials in areas that are aesthetically sensitive. ${ }^{37}$ Camilleri conducted a study in which MTA showed more discolouration as compared to Biodentine. ${ }^{38}$

\section{DISCUSSION}

In endodontic therapy, endodontic repair materials are being used, which ideally adhere tooth structure, maintain an optimal seal, are insoluble in tissue fluids, dimensionally stable, radiopaque, non-toxic to tissue and exhibit biocompatibility. A number of materials have historically been used for retrograde filling and perforation repair such as Gutta-percha, amalgam, Cavit, IRM, Super-EBA, glass ionomer, composite resin, carboxylate cements, zinc phosphate and zinc oxide eugenol cements. Due to some disadvantages, Gutta-percha, amalgam, GIC, composite resin, were not used nowadays as Gutta-percha has a poor sealing ability as it has to be used with a sealer during obturation. ${ }^{39}$ Due to some disadvantages of amalgam like marginal leakage, secondary corrosion, moisture sensitivity, and safety issues due to mercury toxicity are not used as a retrograde filling material. ${ }^{40}$ Considering the bond strength of polycarboxylate and Cavit, they are inferior to amalgam. ${ }^{41,42}$ Unfortunately, none of these materials have been able to satisfy all the requirements of root-end filling materials. Therefore, mineral trioxide aggregate (MTA) and Biodentine became a choice of root-end filling material.

MTA is a new biocompatible material and ideal root repair material which has properties like, ease of clinical manipulation, non-resorbable, nontoxic and allows normal healing response. ${ }^{43}$ During the treatment of horizontal root fracture when MTA is used to form apical seal, there are less chances of re-infection. Due to some disadvantages of MTA, it is not considered as an ideal retrograde root canal filling material. Boutsioukis et al reported that MTA when applied throughout the root canal, becomes very difficult to remove. ${ }^{44}$ Bortoluzzi et al also advocated that discolouration is caused by grey MTA due to the presence of a toxic element arsenic when it is applied on the coronal region of the root canal. Therefore, it is suggested to apply MTA only in apical part of root canal. ${ }^{45}$ There is no need to apply retrograde filling in root canal, if treatment fails or root end resection has to be performed when MTA is filled $5 \mathrm{~mm}$ apically, as it is difficulty to handle, obturation of curved root canals is difficult, longer setting time because of it should not be applied in 1 visit. Inter-appointment moist cotton pellet is required till the final setting of MTA, difficulty in removal after curing due to the absence of a known solvent for set MTA, high cost. ${ }^{46}$ To overcome the drawbacks of MTA like discolouration, lesser compressive strength, more risk of bacterial contamination, difficult handling characteristics, longer setting time, high material cost, an absence of a known solvent for this material, and the difficulty of its removal after setting, Biodentine was introduced as it is a bioactive material. 46

Biodentine has lesser setting time as compared to MTA which improves its mechanical properties and it is a bioactive material. Han and Okiji ${ }^{47}$ compared Biodentine and MTA in 
terms of Ca and Si uptake by adjacent root canal dentine and concluded that tag-like structures are formed in Biodentine. They observed that dentinal element uptake was more prominent for Biodentine than MTA. Zhou et al compared Biodentine with white MTA and glass ionomer cement using human fibroblasts, and found that both white MTA and Biodentine were found to be less toxic compared to glass ionomer. 48

\section{Advantages of Biodentine over MTA}

- Biodentine consistency is better suited to the clinical use than MTA.

- Biodentine ensures a better handling property and it is safer than MTA.

- Highest compressive strength when it is compared to MTA.

- Does not require 2-step restoration procedures.

- MTA showed more discolouration than Biodentine.

- Biodentine proves superior to MTA as the setting is faster and therefore a lower risk of bacterial contamination.

\section{CONCLUSION}

MTA has various clinical applications as it has numerous properties which are required for an ideal root-end filling material. MTA needs to be further explored by clinicians so that its advantageous properties can be practised. On the basis of in-vitro, in-vivo and clinical trials, Biodentine was suggested to be better than MTA regarding biocompatibility and easy handling with short setting time and better biological, mechanical and physical properties. It provides a better environment for cell, showing cell proliferation and osteogenic capability.

\section{REFERENCES}

[1] Regan JD, Gutmann JL, Witherspoon DE. Comparison of Diaket and MTA when used as root-end filling materials to support regeneration of the periradicular tissues. Int Endod J 2002;35(10):840-7.

[2] Aqrabawi J. Sealing ability of amalgam, super EBA cement and MTA when used as retrograde filling materials. Braz Dent J 2000;188(5):266-8.

[3] Priyanka SR, Veronica. A literature review of root-end filling materials. JDMS 2013;9(4):20-5.

[4] Dammaschke T, Gerth HU, Züchner H, et al. Chemical and physical surface and bulk material characterization of white ProRoot MTA and two Portland cements. Dent Mater 2005;21(8):731-8.

[5] Felman D, Parashos P. Coronal tooth discoloration and white mineral trioxide aggregate. J Endod 2013;39(4):484-7.

[6] Camilleri J. Formosa L, Damidot D. The setting characteristics of MTA Plus in different environmental conditions. Int Endod J 2013;46(9):831-40.

[7] Sluyk SR, Moon PC, Hartwell GR. Evaluation of setting properties and retention characteristics of mineral trioxide aggregate when used as a furcation perforation repair material. J Endod 1998;24(11):76871.

[8] Torabinejad M, Chivian N. Clinical applications of mineral trioxide aggregate. J Endod 1999;25(3):197205.
[9] Schmitt D, Lee J, Bogen G. Multifaceted use of ProRoot MTA root canal repair material. Pediatr Dent 2001;23(4):326-30.

[10] Torabinejad M, Hong CU, McDonald F, et al. Physical and chemical properties of a new root-end filling material. J Endod 1995;21(7):349-53.

[11] Septodont. Biodentine ${ }^{\mathrm{TM}}$ Active Biosilicate Technology ${ }^{\mathrm{TM}}$. Scientific file 2010.

[12] Chessmann CR, Asavapisit S. Effect of calcium chloride on the hydration and leaching of lead-retarded cement. Cement and Concrete Research 1999;29:88592.

[13] Singh H, Kaur M, Markan S, et al. Biodentine: a promising dentin substitute. J Interdiscipl Med Dent Sci 2014;2:140-5.

[14] Ravichandra PV, Jayaprada RS, Harikumar V, et al. Mineral trioxide aggregate. Ind J Den Advancement 2011;3(3):593-7.

[15] Biodentine ${ }^{\mathrm{TM}}$ induces TGF-Beta 1 release from Human pulp cells and early dental pulp mineralization. 2011:1365-2591.

[16] Priyalakshmi S, Ranjan M. Review on Biodentine-a bioactive dentin substitute. IOSR Journal of Dental and Medical Sciences 2014;13(1):13-17.

[17] Chong BS, Ford PTR, Watson TF. The adaptation and sealing ability of light-cured glass ionomer retrograde root fillings. Int Endod J 1991;24(5):223-32.

[18] Baek SH, Plenk H, Kim S. Periapical tissue responses and cementum regeneration with amalgam, Super EBA and MTA as root-end filling materials. J Endod 2005;31(6):444-9.

[19] Balto HA. Attachment and morphological behavior of human periodontal ligament fibroblasts to mineral trioxide aggregate: a scanning electron microscope study. J Endod 2004;30(1):25-9.

[20] Ford PTR, Andreasen JO, Dorn SO, et al. Effect of various zinc oxide materials as root-end fillings on healing after replantation. Int Endod J 1995;28(6):273-8.

[21] Koh ET, McDonald F, Ford PTR, et al. Cellular response to mineral trioxide aggregate. J Endod 1998;24(8):543-7.

[22] Bonson S, Jeansonne BG, Lallier TE. Root-end filling materials alter fibroblast differentiation. J Dent Res 2004;83(5):408-13.

[23] About I, Raskin A, Demeo M, et al. Cytotoxicity and genotoxicity of a new material for direct posterior fillings. European Cells and Materials 2005;10(4):23.

[24] Laurent P, Camps J, About I. Biodentine (TM) induces TGF- $\beta 1$ release from human pulp cells and early dental pulp mineralization. Int Endod J 2012;45(5):439-48.

[25] Shipper G, Grossman ES, Botha AJ, et al. Marginal adaptation of mineral trioxide aggregate (MTA) compared with amalgam as a root-end filling material: a low vacuum (LV) versus high vacuum (HV) SEM study. Int Endod J 2004;37(5):325-36.

[26] Valois CR, Costa ED. Influence of the thickness of mineral trioxide aggregate on sealing ability of rootend filling in vitro. Oral Surg Oral Med Oral Pathol Oral Radiol Endod 2004;97(1):108-11. 
[27] Aminoshariae A, Hartwell GR, Moon PC. Placement of mineral trioxide aggregate using two different techniques. J Endod 2003;29(10):679-82.

[28] Koubi G, Colon P, Franquin JC, et al. Clinical evaluation of the performance and safety of a new dentine substitute, Biodentine, in the restoration of posterior teeth - a prospective study. Clin Oral Investig 2013;17(1):243-9.

[29] Budig CG, Eleazer PD. In vitro comparison of the setting of dry ProRoot MTA by moisture absorbed through the root. J Endod 2008;34(6):712-4.

[30] Grech L, Mallia B, Camilleri J. Investigation of the physical properties of tricalcium silicate cement-based root-end filling materials. Dent Mater 2013;29(2): e20-8.

[31] Al-Hezaimi K, Al-Shalan TA, Naghshbandi J, et al. Antibacterial effect of two mineral trioxide aggregate (MTA) preparations against Enterococcus faecalis and Streptococcus sanguis in vitro. J Endod 2006;32(11):1053-6.

[32] Torabinejad M, Hong CU, Ford PTR, et al. Antibacterial effects of some root-end filling materials. J Endod 1995;21(8):403-6.

[33] Aggarwal V, Singla M, Miglani S, et al. Comparative evaluation of push-out bond strength of ProRoot MTA, Biodentine, and MTA Plus in furcation perforation repair. J Conserv Dent 2013;16(5):462-5.

[34] Tunc ES, Sonmez IS, Bayrak S, et al. The evaluation of bond strength of a composite and a compomer to white mineral trioxide aggregate with two different bonding systems. J Endod 2008;34(5):603-5.

[35] Guneser MB, Akbulut MB, Eldeniz AU. Effect of various endodontic irrigants on the push-out bond strength of Biodentine and conventional root perforation repair materials. J Endod 2013;39(3):380-4.

[36] Marciano MA, Duarte H, Camilleri J. Dental discoloration caused by bismuth oxide in MTA in the presence of sodium hypochlorite. Clinical Oral Investigations 2015;19(9):2201-09.

[37] Vallés M, Mercadé M, Duran-Sindreu F, et al. Influence of light and oxygen on the color stability of five calcium silicate-based materials. J Endod 2013;39(4): 525-8.
[38] Camilleri J. Investigation of Biodentine as dentine replacement material. J Dent 2013;41(7):600-10.

[39] Grossman. Grossman's endodontic practice. $12^{\text {th }}$ edn. Lippincott Williams \& Wilkins 2010.

[40] Poggio C, Lombardini M, Alessandro C, et al. Solubility of Root-end filling materials: a comparative study. Journal of Endodontology 2007;33(9):1094-7.

[41] Barry GN, Selbst AG, D'Anton EW, et al. Sealing quality of polycarboxylate cements when compared to amalgam as a retro-filling material. Journal of Oral Medical, Oral Surgery and Oral Pathology 1976;42(1):109-16.

[42] Alhadainy HA, Himel VT. Evaluation of the sealing ability of amalgam, Cavit and glass ionomer cement in the repair of furcation perforations. Journal of Oral Medicine, Oral Surgery and Oral Pathology 1993;75(3):362-6.

[43] Yildirim T, Gençoglu N. Use of mineral trioxide aggregate in the treatment of horizontal root fractures with a 5-year follow-up: report of a case. J Endod 2009;35(2):292-5.

[44] Kokkas AB, Boutsioukis A, Vassiliadis LP, et al. The influence of the smear layer on dentinal tubule penetration depth by three different root canal sealers: an in vitro study. J Endod 2004;30(2):100-2.

[45] Bortoluzzi EA, Broon NJ, Bramante CM, et al. Sealing ability of MTA and radiopaque Portland cement with or without calcium chloride for root-end filling. J Endod 2006;32(9):897-900.

[46] Parirokh M, Torabinejad M. Mineral trioxide aggregate: a comprehensive literature review-Part III: Clinical applications, drawbacks and mechanism of action. J Endod 2010;36(3):400-13.

[47] Han L, Okiji T. Uptake of calcium and silicon released from calcium silicate-based endodontic materials into root canal dentine. Int Endod J 2011;44(12):1081-7.

[48] Zhou HM, Shen Y, Wang ZJ, et al. In vitro cytotoxicity evaluation of a novel root repair material. J Endod 2013;39(4):478-83. 